\title{
ISAAC ASIMOV, LIMERICISTA: LA FUNDACIÓN DEL GRÓSERIC
}

\author{
JESÚS IsAíAs GómEZ LóPEZ \\ Universidad de Almería \\ jesuias@gmail.com
}

\section{RESUMEN}

En este ensayo rescatamos una singular faceta literaria, la lírica, del autor de ciencia ficción y ensayista americano Isaac Asimov. Para ello hacemos un recorrido literario por la incursión poética de Asimov por la estética del límeric, una peculiar forma poética de la lengua inglesa, escasamente tratada en nuestra lengua. Es cierto que el límeric, como forma poética de sólo cinco versos, no comparable a ninguna forma poética del español —aunque posiblemente se aproxime a la redondilla—, de tono jocoso, cómico y frecuentemente lúbrico, podría parecer una forma poética menor; pero cuando un autor de la talla de Isaac Asimov dedicó buena parte de su actividad literaria a la composición de esta hilarante y desenvuelta forma poética, resulta obligado dar a conocer esta otra insólita faceta literaria suya. Sin duda, el presente ensayo viene a cubrir un importante vacío literario sobre el autor tanto en español como en inglés.

PALABRAS ClAVE: límeric, gróseric, lúbrico, Isaac Asimov, forma poética, obsceno.

\section{ABSTRACT}

The aim of this essay is to reclaim one of American science fiction and essay writer Isaac Asimov's least well-known literary aspects, his poetic works. In that sense, we offer an elementary survey of Asimov's journey through the aesthetics of the limerick, a popular poetic form of the English language which, by the way, is scarcely used in Spanish, though the Spanish quatrain ("redondilla") is slightly comparable. Although the limerick could be considered a minor poetic form due to its common funny, comic and lubricous tone, the fact that such distinguised literary authority as Isaac Asimov could have dedicated part of his 
literary creativity to the composition of this hilarious and boastful poetic form is a crucial reason to put on the map this unusual literary side by the author. Certainly, this essay fills what would otherwise be a serious gap in the studies of Asimov in both English and Spanish.

KEY WORDS: limerick, gróseric, lubricous, Isaac Asimov, poetic form, gross.

\section{INTRODUCCIÓN}

El autor de la saga La Fundación, de numerosas novelas y relatos cortos de ciencia ficción, así como de relevantes ensayos científicos, escribe su primer poema — de corte lascivo- en junio de 1974, a los cincuenta y cuatro años, «a bordo del Queen Elizabeth $I I{ }^{1}$, en un viaje de vuelta de Gran Bretaña a los Estados Unidos. Como el propio Asimov afirma en su momento, son las carcajadas de sus oyentes las que le animan a seguir escribiendo límerics hasta 1981.

Isaac Asimov acaba de encontrar en el límeric el mejor modo de hacer reír a sus contertulios, familiares y amigos, y aunque el límeric, como forma poética, puede albergar una infinidad de temas de cualquier naturaleza y disciplina, nuestro improvisado poeta se sirve de esta para proyectar su particular visión del sexo desde una dimensión netamente cómica, donde la palabra grosera y la imagen obscena parecen diluirse entre fuertes arranques rítmicos y bien ensayadas rimas. Tal vez por este motivo, Isaac Asimov afirma, nada más iniciar esta improvisada aventura poética, que «the conciseness and density of thought of a limerick forces every word to bear its full weight of meaning» (ASIMOV, 1977:7). Y posiblemente también — podríamos añadir — la máxima carga de invitación sensual y sexual.

El asunto sexual, que en su obra de ficción es prácticamente inexistente, encuentra aquí, en cambio, una expresión directa y explícita en esta vertiente poética. La ausencia de ingredientes sexuales de sus relatos y novelas puede tener la misma explicación que la escasez de alienígenas o extraterrestres, cuya existencia, antes o después, de una u otra manera, también habría que integrar con elementos sexuales. En su obra de ciencia ficción son los robots y una humanidad robotizada quienes eclipsan, por completo, el sexo como asunto y el sexo como ars amatoria. En cambio, nuestro autor parece encontrar aquí, en esta breve forma poética, el mejor modo de plasmar espontáneamente lo que hasta 1974 ha permanecido silenciado, como una inmensa fuerza bruta inconscientemente reprimida. En este sentido, si es cierto que los «limericks feed on themselves» (1975:23) ('los límerics se nutren de sí mismos'), —como afirma el autor en su primer volumen de límerics — tampoco hay duda de que el sexo también. El propio Asimov admite sin ruborizarse en frecuentes entrevistas, de igual modo que en sus títulos autobiográficos, haber llegado, junto a su primera esposa Gertrude, virgen al matrimonio, acaecido el 26 de octubre de 1942 cuando él tenía veintidós años y ella veinticinco ${ }^{2}$. No es de extrañar, por tanto, que el asunto sexual revelado en estos poemas con un tratamiento tosco y grosero, enmarcado dentro de una clara intención humo-

\footnotetext{
1 Asimov, Isaac (1977). Lecherous Límerics, Nueva York, Corgi, p. 13.

${ }^{2}$ Cfr. Hoppa, Jocelyn (2009). Isaac Asimov, Science Fiction Trailblazer, Enslow Publishers, Berkeley Heights.
} 
rística, sorprenda a una buena parte de sus fieles lectores y a cualquier entusiasta de la ciencia ficción. Naturalmente, a este grupo de asombrados lectores también se suma quien subscribe el presente trabajo. Bien por tratarse de una extravagancia literaria o, más seguramente, por estar ante un contenido a distancias siderales del que el autor nos tiene acostumbrados, es cierto que esta curiosa faceta lírica de Isaac Asimov ha pasado sin pena ni gloria tanto en España como en el mundo anglosajón, o lo que es peor, prácticamente desapercibida. La vasta carrera literaria de Isaac Asimov, como uno de los padres de la ciencia ficción literaria del pasado siglo, con sus más de quinientas obras publicadas - entre novelas, relato corto, ensayo científico y autobiografías - es motivo suficiente para que esta intrépida, aunque minúscula, incursión poética de nuestro autor no haya pasado de ser una rara y simpática anécdota literaria que intentaremos despejar en el presente estudio.

\section{BREVES APUNTES SOBRE EL LÍMERIC}

Del origen de esta escueta forma poética se sabe más bien poco. Son numerosos los portales de internet y los blogs literarios que intentan dar, con escasa fortuna, respuesta a la época en la que nace esta divertida forma lírica cuyo distintivo patrón rítmico y métrico - elucubraciones al margen - ya parecía ser conocido en las islas británicas incluso en la época de William Shakespeare, de quien incluso se cree hubiese conocido ya esta forma poética hasta el punto de haber recurrido a esta en alguna ocasión: «And let me the canakin clink, clink; /And let me the canakin, clink / A soldier's a man; / A life's but a span; / Why, then let a soldier drink» ${ }^{3}$.

Al hecho de que la historia del límeric está bien poblada de conjeturas, se le suma, para mayor desgracia nuestra, el no encontrar una respuesta satisfactoria y definitiva sobre sus verdaderas raíces geográficas. Aunque las especulaciones son infinitas, las referencias y el material bibliográfico que merece todo nuestro crédito no se atreven a afirmar una definitiva región o área geográfica como la cuna definitiva del límeric, pero sí hallamos, por suerte, importantes estudios sobre la evolución de esta forma poética como un proceso lírico bien definido, que surgido, posiblemente, en Irlanda y rápidamente extendido por todas las islas británicas, hasta convertirse en el chiste lírico por excelencia de la lengua inglesa, a día de hoy, ha conseguido contagiar con su característica rima y ritmo casi todas las lenguas del orbe.

La primera compilación de límerics se la debemos al pintor inglés Edward Lear (18121888), quien en su obra $A$ Book of Nonsense $e^{5}$ publicó cien límerics que él mismo también se encargó de ilustrar con sus dibujos en 1846 y que, dicho sea de paso, prefirió denominar «nonsense» en vez de «limerick». Desde entonces, muchos han sido los poetas de la lengua inglesa que se han atrevido con esta corta variante lírica, presente en la mayoría de todos

\footnotetext{
${ }^{3}$ Escena III, del Acto II de Othello. Cfr. Shakespeare, William (2000). Othello, Londres, Wordsworth Classics, p. 88.

${ }^{4}$ Pese a estar muy extendida la opinión de que esta forma poética es de origen irlandés por llevar el nombre de la ciudad irlandesa de Limerick, esta afirmación no escapa del terreno de la más pura especulación. En efecto, podría ser esta ciudad el origen del límeric, pero no hay datos ni registros literarios que avalen esta creencia.

${ }^{5}$ Publicado por Thomas McLean en Londres, el 10 de febrero de 1846.
} 
ellos aunque sólo sea para dar colorido al plano personal y social y, casi siempre, quedando finalmente fuera de procesos líricos tal vez más nobles. De este modo, de nombres como Kipling, T. S. Eliot, Dylan Thomas o W. H. Auden se conocen algunos límerics, que, sin embargo, difícilmente encontraremos publicados entre sus principales volúmenes de poesía. El célebre poeta inglés W. H. Auden decidió en su momento publicar ocho límerics dentro de una edición destinada a dar cabida a esta y otras populares formas poéticas, como baladas y cancioncillas: «As the poets have mournfully sung, / Death takes the innocent young, / the rolling-in-money,/ The screamingly-funny,/ And those who are very well hung» ${ }^{6}$.

Pero otros poetas en cambio, como el norteamericano Ogden Nash (1902-1972), forman parte del escaso número de autores que recurren al límeric, sin ningún tipo de prejuicios, como una decidida apuesta más de su carrera poética: «A bugler named Dougal Mac Dougal / Found ingenious ways to be frugal. / He learned how to sneeze / In various keys, / Thus saving the Price of a bugle» ${ }^{7}$.

El límeric no sólo contagia a poetas, también son abundantes los novelistas que en algún momento u otro — como el caso de Isaac Asimov- recurren al límeric para compartir, la mayoría de las veces, con sus más allegados, y, en contadas ocasiones, con el lector, el apartado festivo y social de su talento literario. No es de extrañar, por tanto, que, a ambos lados del Atlántico, nombres capitales de la narrativa en lengua inglesa como Mark Twain, Robert Louis Stevenson, H. G. Wells y hasta el mismo James Joyce se sumasen a la larga lista de repentinos y efímeros limericistas.

Dado el contenido frecuentemente impúdico y el humor fácil y grosero con que se asocia esta forma poética, la mayoría de autores que escriben un límeric suelen descartarlo de sus publicaciones. W. H. Auden, en su introducción para The Oxford Book of Light Verse, de 1938, pese a hacer una valoración decidida y positiva del límeric, evita mencionar el término - que seguramente considera restrictivo y excesivamente malinterpretado- para incluirlo dentro de un espectro más amplio, diáfano y ambiguo, y por tanto mucho menos comprometedor: «Light verse» ('poesía festiva', 'parodia rimada'):

Light verse can be serious. It has come to mean vers de société, triolets, smoke room limerick, because, under the social conditions which produced the Romantic Revival, and which have persisted, more or less, ever since, it has been only in trivial matters that poets have felt in sufficient intimacy with their audience to be able to forget themselves and their singing robes [...] only in a society which is both integrated and free ${ }^{8}$.

W. H. Auden al menos considera el límeric parte inherente de esta «parodia rimada»o «poesía festiva» que reconoce alejada de los círculos literarios más nobles no precisamente

${ }^{6}$ W. H. Auden prefirió mantener este tipo de poesía fuera de sus ediciones canónicas (The Collected Poems, Selected Poems). Sus ocho límerics aparecen publicados, junto a una serie de baladas y poemas de corte popular, en una edición a cargo de su biógrafo Edward Mendelson: Mendelson, E. (1996). W. H. Auden, As I walked Out One Evening: Songs, Ballads, Lullabies, Limericks, and other Light Verse, Londres, Faber \& Faber. El volumen lleva como título principal el poema «As I walked Out One Evening», que compuso en 1937 y apareció en su volumen Another Time, de 1940.

7 Cfr. Nash, Ogden (2008). Candy is Dandy: The Best of Ogden Nash, Londres, André Deutsch, p. 63.

${ }^{8}$ Mendelson, Edward (1983). Early Auden, Cambridge, Harvard University Press, pp. 206-207. 
por una falla en el estilo de la forma poética, sino por la falla de su sociedad y de la nuestra, que aún sigue esperando la integración y la «libertad» necesarias para liberar el límeric de consentidas y esperadas etiquetas como «dirty» ('sucio') o «ribald» ('obsceno') con que, frecuentemente, suelen estigmatizarlo sus propios creadores, que, por ende, contribuyen a hacer de esta forma poética el refugio poético por excelencia de una vasta mayoría de poetas anónimos.

\section{ISAAC ASIMOV: LIMERICISTA}

En nuestra introducción hemos descubierto cuándo y dónde nace el primer límeric de Asimov, y cómo la alborozada respuesta de los oyentes le sirve de estímulo para prodigarse en este nuevo género literario, que, en modo alguno, le resulta ajeno. Pero el verdadero motivo que lleva a Asimov a plantearse la posibilidad de incorporar el límeric como un nuevo género dentro de su vasta producción literaria se remonta al 12 de marzo de 1971, tras un almuerzo celebrado con una pareja de entrañables amigos, el matrimonio Walker, propietarios de la editorial Walker and Company. La anfitriona, Beth Walker, conocedora del especial talento para el chiste y la broma de su invitado, sugiere a este la posibilidad de publicar un «obscene book» a modo de parodia de un título entonces bastante popular, The Sensuous Wo$m a n^{9}$, de Joan Garrity, en la época todo un éxito de ventas de cuestionable calidad literaria. Aunque Asimov esgrime contra esta invitación sus escasos conocimientos de sexo: "What do I know about sex?» (WHITE, 2005:206), y su desinterés por este tipo de literatura que él mismo descalifica por completo: «Asimov declared that he didn't write trash» $(2005: 206)$, la insistencia de los Walker logra hacerle cambiar de opinión, llevándole a firmar, ante sus comensales, en los postres, precipitadamente, el contrato para una obra de la que, en ese instante, únicamente puede aportar el título, The Sensuous Dirty Old Man ('El viejo verde y sensual'). Apenas tres meses después de esta desafiante propuesta, el 2 de junio de 1971, aparece la primera edición de The Sensuous Dirty Old Man, que firma como «Dr. A», parodiando así The Sensuous Woman, que su autora firmara con una «J.». Tanto el matrimonio Walker como Asimov se anticipan en el tiempo al criticar la visión sexista y acomplejada de la mujer que ofrece The Sensuous Woman; pero, el contenido del título de respuesta de Asimov sencillamente expone la otra cara de esa misma moneda: una visión netamente machista e irreverente del sexo, que para el autor no deja de ser más que una «innocent joke» (1971:5) y para la editorial todo un éxito de ventas. Poco tiempo después, el matrimonio Walker intenta convencerle de que haga una secuela literaria a partir del exitoso título; pero Isaac Asimov ha tomado la decisión de poner punto y final a la obra aunque no a la broma, que continuará bajo el formato y la entelequia del límeric, como nueva y atrevida apuesta personal del autor por el sarcasmo y la risa, esta vez, sin cargos.

Isaac Asimov publica su primer título de límerics en la editorial Walker Publishing Company en 1975. El volumen, que titula Lecherous Limericks y dedica a su flamante se-

${ }^{9}$ El libro, publicado en 1969 por Joan Garrity, es un manual de instrucciones o tutorial de sexo para la mujer, notablemente discriminatorio, aunque en su momento llegó a ser todo un best seller. Cfr. Garrity, Joan Terry (1970). The Sensuous Woman: The First How-To Book For the Female Who Yearns to Be All Woman, Nueva York, W. H. Allen. 
gunda esposa, la psiquiatra Janet Asimov, viene acompañado de diez divertidas ilustraciones - a tono con el contenido lascivo de los versos - llevadas a cabo por el entonces célebre dibujante de cómics Arthur Robins. Todos y cada uno de los cien límerics de que consta el poemario vienen seguidos por un comentario, al caso, del propio poeta, con espontáneas reflexiones provocadas por el límeric en cuestión, de lo más variopintas y desde las más diversas perspectivas. Pero todas ellas con una decidida finalidad por parte del poeta: establecer un vínculo directo y amistoso con el lector, que recibe así una sincera e íntima confesión del creador lírico, diluyéndose, de este modo, cualquier atisbo de disculpa por el contenido a menudo excesivamente procaz de los versos. Estas reflexiones, por tanto, pueden llevar la marca de la fuerza inspiradora que las origina, que frecuentemente es el nombre o apellido de alguno de los contertulios: «Originally, I wrote this limerick around the name of a personal and much- beloved friend of mine» (ASIMOV, 1975:30), o pueden ser provocadas por los más intrascendentes asuntos cotidianos: «I wrote this one while waiting to go on a radio talk show» (1975:169); pero, la inmensa mayoría de estos comentarios lleva el sello de la prosodia como herramienta semiótica que intenta, y frecuentemente logra, extraer todo un manantial de retórica incluso de la palabra más vulgar:

This started with the rhyme of "semen and he-men which I couldn't resist once it had occured to me. In fact, for a while I added the phrase "we men" and tried to place it in the first, second and fifth lines, but couldn't do it without straining the verse beyond the breaking point (1975:157).

Queda claro que para Asimov, el límeric no es simplemente una forma poética gestada para animar una velada y arrancar las carcajadas de los presentes. Esta no es más que la preceptiva máscara de una intención doblemente sublime: dotar a la palabra, a partes iguales, de su naturaleza visual y de su carácter musical, con lo que el verso se sustenta en una estructura semiótica y semántica además de lírica: «Which means that you are working your way through the alphabet searching for rhymes» (1975:29).

En el año 1976, aparece un nuevo título de límerics, More Lecherous Limericks que la Walker Publishing Company publica en pequeñas tiradas de cien, tras rechazar nuestro autor la suculenta oferta económica de la revista Playboy para hacerse con todos los derechos de estos límerics, a cambio de borrar de su pretendida publicación el nombre del autor de los mismos, lo que provoca la indignación de Isaac Asimov:

Playboy likes to publish limericks without the author's name attached, pretending, suppose, that they had arisen out of the hidden wellsprings of some divine editorial inspiration. PLAYBOY also liked to buy all rights. This meant that they could include the limericks in their own collections of humor, with no further payment of any kind to the author. Nor could the author ever use the limericks he had constructed himself in any of his own books. Well, I'm not so closet o starvation that I need accede to such dictatorial demands, you may be sure, so my limericks remain my own and no one else's (ASIMOV, 1976:7).

Este segundo título de límerics es una secuela o continuación de su primer volumen. El primero constaba de 100 límerics, y este segundo consta de otros cien más, numerados desde el 101 hasta el 200 con tal de preservar la continuación del título que lo precede. Estos nuevos cien límerics, al igual que los anteriores, también van acompañados del comentario estilístico, anecdótico y hermenéutico del autor. 
Al año siguiente, en 1977, Asimov, entusiasmado con los efectos discursivos y fonéticos de esta sicalíptica forma poética, publica, nuevamente para Walker Publishing, Still More Lecherous Limericks, en una tirada de 100 ejemplares, título que concluye su aventura en solitario por la imprecisa geografía del límeric. Tan sólo un año después, en 1978, nuestro autor, aún subyugado por la intensidad rítmica y el simpático patrón fonosimbólico de esta forma poética, publica un nuevo volumen de sesenta límerics, Asimov's Sherlockian Limericks, a modo de homenaje a la saga literaria de Sherlock Holmes, del escritor escocés Sir Arthur Conan Doyle, con el que el poeta aspira a distanciarse del asunto y el tono de los anteriores volúmenes y, seguramente también, en un intento por mostrar una cara del límeric más noble y literaria, como él mismo afirma en la «Introducción» de esta edición:

The limerick has become rather a specialty of mine, since this is my fourth book of them (and the first to be entirely respectable). In this one, I present sixty limericks, one for each of the sixty Canonical tales of Sherlock Holmes (1978).

En efecto, cada uno de estos límerics es un intento por captar y retratar en cinco versos la esencia del relato corto que lo inspira. De este modo, los sesenta límerics suponen un gráfico recorrido sinóptico por todos y cada uno de los relatos cortos que componen la saga de cuatro títulos creada por Sir Arthur Conan Doyle sobre el personaje de Sherlock Holmes,${ }^{10}$ siguiendo así escrupulosamente el orden de aparición cronológica de los mismos: The Adventures of Sherlock Holmes (1892); The Memoirs of Sherlock Holmes (1894); The Return of Sherlock Holmes (1905); His Last Bow (1917); The Case-Book of Sherlock Holmes (1927). A estos límerics hay que añadir otros cuatro (hasta completar los sesenta), que inician el volumen y simbolizan, cada uno de ellos, las cuatro novelas de Sir Arthur Conan Doyle, también por orden de aparición cronológica: A Study in Scarlet (1887); The Sign of Four ${ }^{11}$ (1890); The Hound of the Baskervilles (1902); y The Valley of Fear (1915) ${ }^{12}$. El límeric que abre el poemario, «A Study in Scarlet» («Estudio en escarlata»), y el que lo cierra, «The Adventure of the Retired Colourman» («El fabricante de colores retirado») son reveladores de la intención lírica del poeta de aportar su percepción de estos relatos, como experiencia personal donde el objeto y el motivo centrales toman forma y sentido en la esencia misma de esa percepción íntima de la lectura de Sir Arthur Conan Doyle. Aunque Asimov concibe estos límerics, según advierte en la Introducción al poemario, como un atrevido intento de imitar el canon sherloquiano: «Limericks based on the Sherlockian canon», en reconocido tributo a una de las últimas producciones de la era victoriana, y en modo alguno, por tanto, interesado en utilizarlos como breve extracto del argumento del relato representado, cualquier lector mínimamente familiarizado con las historias de Conan Doyle no necesitará conocer los títulos de los límerics para identificar, sin margen de error, el relato aludido. Captar, en tan sólo cinco versos, la esencia de todos y cada uno de estos relatos de Conan Doyle puede que no sea el objetivo del hablante lírico; pero, con todo, lo consigue y es en el aspecto formal y en el material donde su experiencia personal queda expuesta como una racionalización hacia

\footnotetext{
${ }^{10}$ Cfr. Sir Arthur Conan Doyle, 2009. The Penguin Complete Sherlock Holmes, Londres, Penguin.

${ }^{11}$ El título del respectivo límeric, equivocada o intencionadamente, es: «The Sign of the Four» («El signo de los cuatro»). [El subrayado es nuestro.]

${ }_{12}$ Cfr. Sir Arthur Conan Doyle, The Complete Sherlock Holmes (All 4 Novels and 56 Short Stories), Nueva York, Bantam, 1998.
} 
un acto ideal de su propia conciencia, donde se sustentan la estructura objetiva y la esencia cognoscible de todos y cada uno de estos límerics gestados para capturar esencias literarias cercanas o alejadas de la opinión general del lector, en función de la familiaridad de este con la obra de Conan Doyle:

\section{Silver Blaze}

A bright tale of a dog and a horse
(And there's also a murder, of course)
which involves the old fact
That the dog failed to act,
Which Holmes found of significant force. ${ }^{13}$

Ese mismo año (1978), sin embargo, Isaac Asimov vuelve, contra todo pronóstico, con un nuevo volumen de límerics obscenos, en esta ocasión, y como hemos apuntado anteriormente, en colaboración con un viejo amigo, el poeta John Ciardi ${ }^{14}$. El poemario, que titulan Limericks: Too Gross ${ }^{15}$ ('demasiado groseros'), contiene, en efecto, como el substantivo inglés gross indica, doce docenas de límerics, 144 compuestos por Isaac Asimov y otros 144 a cargo de John Ciardi. De todos modos, el término gross, que como adjetivo puede traducirse como 'grosero', 'vulgar' o 'tosco', aunque aquí tiene intencionadamente un uso substantivo ('una gruesa', 'doce docenas') ${ }^{16}$, en inglés sigue evocando claramente el matiz más tosco de una invitación sexual. El poeta, evidentemente, juega magistralmente con el lenguaje. La traducción, por consiguiente, del título al español y al inglés trasciende la cuestión puramente semántica e idiomática en la medida en que se adentra en espacios y horizontes reservados a la imaginación del lector, que queda enfrentado, curiosamente en ambos idiomas, a divergentes significaciones de una misma palabra: 'una gruesa de límerics'; 'una grosería/guarrería de límerics'. Siguiendo esta colaboración con John Ciardi, ambos vuelven a publicar para la editorial Norton \& Company, en 1981, un nuevo volumen titulado A Grossery of Limericks, que bien podríamos traducir como 'una lonja de límerics' o, tal vez mejor, 'una guarrería de límerics', con el que siguen el mismo patrón de presentar cada autor una nueva gruesa de límerics. La primera parte del volumen, corre a cargo de Asimov, titulada A New Gross of Limericks, que en español sería 'Una nueva gruesa de límerics'.

Asimov concluye, de repente, su carrera como limericista al poco tiempo de la publicación de este último título, que le llevaría a los tribunales por la denuncia interpuesta por unos padres a un profesor de Instituto tras haberle regalado el libro de Asimov al hijo

13 'Estrella de plata: Bello cuento de un perro y un caballo / (con asesinato, no lo callo) / que trae el extraño hecho / de que el perro quedó maltrecho, / algo que para Holmes fue un fallo'.

${ }_{14}$ John Ciardi (1916-1986), poeta, columnista de relevantes periódicos y profesor de poesía en la University of Florida, destacó por su ingente producción poeta, aunque de escasa relevancia académica y editorial.

15 El título del poemario, en colaboración con John Ciardi, será publicado por Norton \& Company en 1978 con el título: Límerics: Too Gross or Two Dozen Dirty Dozen Stanzas. El poemario viene claramente dividido en dos partes. La primera parte es la de Isaac Asimov, titulada: "Limericks: A Gross".

${ }^{16}$ El Diccionario de la lengua española $(R A E)$, entre las diversas acepciones del término 'grueso' ofrece la siguiente definición de 'gruesa', en su variante femenina: «Número de doce docenas, especialmente de cosas menudas. Una gruesa de botones, de agujas». 
de estos, de 18 años de edad. La polémica estaba servida y Asimov fue citado a declarar, como autor del libro, por el tribunal, en la ciudad de Birmingham (Alabama). Aunque la disputa no pasara de una incómoda citación judicial, Asimov, decidido a evitar futuros malentendidos que pudieran alterar su reputación, decidió abandonar su carrera de limericista $^{17}$. Así es como concluye la carrera poética de Asimov por los descarados escenarios del límeric, en una apuesta personal por enfrentarse a su mundo y a sí mismo con una clave de humor que, antes que asociarse con la excentricidad y la vulgaridad, destapa una concepción cínica y truculenta del ser humano, con el sexo como instrumento que confunde la ironía, el sarcasmo y la comicidad en una de las múltiples enunciaciones de la condición humana.

\section{LA FUNDACIÓN DEL GRÓSERIC: LA SEMIÓTICA SEXUAL DE LA LÍRICA}

De igual modo que en la década de los cincuenta Isaac Asimov fabrica las autopistas galácticas por las que el ser humano y el robot, de la mano, vehiculan la trilogía de la Fundación ${ }^{18}$, en los años setenta, nuestro autor crea lo que en adelante se podría proclamar la «Fundación del gróseric», una nueva forma poética, en la medida en que se funda un nuevo tipo de límeric, el gróseric, acrónimo de «grosero» y «límeric», que nace como un mágico destello de improvisación con la intención de crear, en la perseverancia de la rima y el metro como marcados rasgos estilísticos, una interrelación entre significante y significado, forma y fondo, para articular así un discurso poético teñido de un planteamiento subjetivo que expone y plantea el mensaje en el centro de una semiótica sexual de frenética intensidad lírica. Seguramente porque, tal y como el propio Asimov admite en The Sensuous Old Man, el lenguaje tiene el poder de reflejar la dimensión artística de los sentimientos mejor que ningún otro proceso cognitivo o inconsciente:

Speech is the Crown of the sensuous dirty old man's art. While there is a certain amount of comunication in a sigh, a deal of significance in the wiggling eyebrow, a clarity of expression in the Sharp stare, enormous admiration in the involuntary ejaculation - there is still nothing like the English language for delivering carefully-thought-out and subtle feelings (1971:116).

El profesor y crítico literario M. H. Abrams, al analizar las «dimensiones» de la poesía de John Keats, uno de los precursores del movimiento romántico en la poesía inglesa, considera el habla el «medio material» del poema:

The material medium (in current parlance, "the material signifier") of a poem is speech, and speech consists of enunciated words, so that the sound of a poem is contituted by speech-sounds. And we don't —we can't— hear speech-sounds purely as sounds (ABRAMS, 2012:32).

17 Cfr. White, Michael, 2005. Isaac Asimov, A Life of the Grand Master of Science Fiction, Nueva York, Carroll \& Graf Publishers, p. 208.

${ }^{18}$ Cfr. Asimov, Isaac, 1951. Foundation, Nueva York, Gnome; 1952. Foundation and Empire, Nueva York, Gnome; 1953. Second Foundation, Nueva York, Gnome. 
El límeric es, sin duda, una de las formas poéticas en las que mejor se puede apreciar esta observación. Apoyándose en esta reflexión, el profesor M. H. Abrams valora la existencia de dos cualidades extra auditivas en todo aquello que oímos en el poema:

One of these is the significance of the words, phrases, and sentences into which the speechsounds are conjoined. The other is the physical sensation of producing the speech-sounds that we hear or read (ABRAMS, 2012:32).

Los gróserics de Asimov reproducen estas dos peculiaridades de principio a fin: la primera, «the significance of the words», desde la experimentación subjetiva del hablante lírico, es canalizada hacia un objetivo cuya función es explorar el lado cómico y vulgar del sexo como enclave de una doble perspectiva de la realidad: la subjetiva del hablante lírico y la también subjetiva del receptor (oyente o recitador) del poema; la segunda, «the physical sensation», afecta perceptiblemente a cualquier lector u oyente de estos poemas en la medida en que los patrones fonéticos logran atrapar su percepción interior, llegando, según el caso, a producir una íntima comunión con el verso o, justo lo contrario, un descenso a los infiernos. La interpretación que cada lector haga de estos versos, desde estas dos cualidades, dependerá fundamentalmente de su personal visión y aceptación o negación del asunto sexual. El significante y el significado, como centros de la imagen lírica representada en cada gróseric, pueden llevarnos, con idéntica premura, a dos metas opuestas: a la mente del poeta, a modo de simpática y liberadora confabulación con el lector, o al rechazo inmediato, como respuesta que limita la posibilidad de ver más allá de una interpretación condicionada, esclava de nuestro subconsciente. De hecho, no en vano el propio Asimov, en aras de mantener un compromiso más íntimo, causal e identificativo con el lector, invita a este a reconocerse en los versos y experimentar con ellos posibles modificaciones:

Incidentally, if you can improve on any of these límerics, let me know. In a second (enlarged?) edition, I may introduce changes with credit. Please, however, consider improvements only in the direction of increased cleverness of rhyme or image and not in the direction of increased vulgarity (1975:35).

Asimov encuentra en el gróseric el mejor modo de tratar el sexo como un asunto inequívocamente humano, recurriendo — si es preciso - a la palabra grosera y a la imagen explícita y descarada, creando un instrumento que le dotará de un sentido y forma corpórea para así retener su propia substancia o identidad individual, que es lo que acaba haciéndolo único, pues como forma lírica corpórea es susceptible del cambio, de la transformación y de la impresión que ocasiona en la psique del lector u oyente. Por tanto, el gróseric no es únicamente una unidad substancial (materia y forma líricas) con propiedades reales, sino además una unidad natural, no escindida, que deriva en un último proceso psíquico, objetivamente divisible y diferenciable en distintos componentes (figuras del discurso, prosodia, imágenes, mensajes, etc.) en su sentido más formal, articulando de este modo la naturaleza que Abrams atribuye a esta otra «dimensión material» del poema:

Of all the forms of art, futhermore, the material base of poetry, whether spoken or sung, is the most intimately human, because it is constituted solely by our own bodily actions, and because its vehicle is the breath of our life (ABRAMS, 2012:33). 


\subsection{El estilo telegráfico como naturaleza distintiva del gróseric}

La concisión, precisión y brevedad son tres de las principales características del límeric. En el caso del gróseric, a estas tres propiedades se suma una especial intensidad provocada por los efectos visuales y las sugerencias auditivas que hacen de este tipo de límeric una variante especialmente informal cuando adopta, como suyo, el vocablo y la imagen grosera y tosca al unísono con un escenario burdo e inoportuno. Así, las variantes sociales, culturales y regionales que representan la legión de protagonistas que inspiran cada uno de estos gróserics no son más que un sin fin de registros vulgares con los que el hablante lírico explora las ideas y los temas más zafios y ordinarios, en la calle, en el trabajo y en la intimidad, de los que ningún ser humano escapa, y que, precisamente por su vulgaridad, adoptan un tono tremendamente informal, por ende, personal, creándose de este modo un estilo coloquial mediante el cual nuestro hablante lírico descubre frecuentes conversaciones que parecen otorgar mayor credibilidad al mensaje revelado:

Said a guy to his gal, quite ambitiously,

"I will screw you, my dear, expeditiously."

The lass simply smiled,

Said, "Delightfull! Just wild!"

And it all ended simply deliciously (1978:11).

En otras ocasiones, el hablante lírico, opta por ofrecer una relación amistosa, cordial, con su lector, llegando incluso a compartir con este la amarga o dulce experiencia reflejada en el gróseric:

A psychiatrist said, "It's no matter

That my husband is mad as a hatter.

There are certain psychoses

That bring sex in large doses.

My husband, you see, is a satyr (1975:128).

La coherencia discursiva es una de las principales cualidades del gróseric de nuestro poeta, que define campos isotópicos mediante vocablos con connotaciones semánticas, como elementos significativos, que vienen a incrementar la esencia lasciva del verso, tanto en sentido masculino: «But the thrust of Alphonse / Barely reached to her mons» (1975:20), como en femenino: «And her nipples were mother-of-pearl» (1981:13). Todas estas connotaciones $\mathrm{y}$ asociaciones de ideas trascienden el significado literal de la palabra, pues las connotaciones de una palabra derivan de los modos en los que se ha usado, de los contextos en los que se usa y de las asociaciones que el lector u oyente hace con estas. En este sentido, las emociones y reflexiones que se desprenden de la mayoría de estos gróserics están estrechamente vinculadas y unidas al tipo de dicción empleada en este particular discurso lírico:

In Venus, where love's an addiction,

An orgasm's brought on by friction

Of toes against toes,

Or nose against nose,

And that's what I call science fiction (1978:130). 
De este modo, el fondo y la forma, pese a exigir y reivindicar claramente cada uno su espacio bien definido y delimitado, llegan a diluirse en interrelaciones morfológicas y sintácticas que parecen perseguir y, en la mayoría de los casos, conseguir toda una vibrante melodía armónica:

During sex, Mary's moans were harmonic

From high C, down by chords, to the tonic.

So John felt it unsordid

To have them recorded

In sound that was stereophonic (1975:74).

Porque los gróseric de Asimov logran fundir, a modo de contrapunto formal y conceptual, como si de dos brevísimas líneas melódicas se trataran, un aparente simultaneismo antitético que marca un nuevo ritmo en el discurso poético mediante esta modalización lírica del contenido y de la forma, sin destacarse la hegemonía de una sobre otra. Ambas modalizaciones (forma y fondo) convergen en dos tonos de un mismo discurso lírico, de variables matices polirrítmicos, polisemánticos y polifónicos, donde el fondo se convierte en tono y la forma en tonema de una sui géneris línea melódica:

A Young woman from South Carolina

Placed fiddle strings' cross her vagina.

With the proper-sized cocks

What was sex became Bach's

Toccata and Fuge in D Minor (1975:48).

El gróseric de Asimov ofrece su propia convención lírica en la medida en que responde a un estilo espontáneo, natural y ensayado en la participación e interrelación que exige entre el hablante lírico y su destinatario, partitura e instrumento respectivamente de una representación lírica verosímil, de contagiosa capacidad persuasiva que frecuentemente puede hacer incluso olvidar la intuición poética que los origina:

In fact, at a recent science fiction convention, when I was engaged in talking to the Young women in my usual suave and courtly manner, one of them pinned a badge on my lapel, which read "Dirty Old Men Need Love, Too." I'm not sure why on earth she thought that was appropriate in my case (1975:91).

\subsection{La retórica como recurso surrealista del gróseric}

Es un hecho especialmente destacable que todas estas figuras retóricas de dicción que definen el gróseric de Asimov, como una nueva modalidad de límeric, comportan una incuestionable fuerza expresiva indudablemente motivada por la intuición poética de su creador. Asimov concibe el límeric como una manera de experimentar, con absoluta libertad de expresión formal y conceptual, las más amplias perspectivas y dimensiones de un uso del lenguaje liberado de las cadenas de la mente consciente, procedente de una vocación lírica gestada en el inconsciente, que invita, por tanto, a su destinatario lírico a una simpática y atrevida expe- 
riencia por unos versos que modulan todo un manifiesto surrealista en tres registros, a modo de lascivo tríptico musical. La exploración surrealista de estos versos surge siempre desde la llamada y la invitación sexual. La poesía tiene la peculiaridad, por encima de cualquier otra apuesta literaria o incluso actividad humana, de dar lugar, mediante los actos del habla y figuras del discurso, a asombrosos malentendidos, y en el caso del gróseric de Asimov a incómodos errores interpretativos que comprometerían seriamente la labor incluso del traductor más experimentado que se atreviese a plasmarlos en español o en cualquier otro idioma. Hecha esta reflexión, resulta aconsejable añadir que Asimov interpreta sus gróserics desde un enfoque del lenguaje poético que se sustenta en la convicción de una absoluta libertad de acción y, por consiguiente, de libertad también interpretativa. La forma y el concepto líricos cobran aquí una misión diferente a la que habitualmente se enfrenta el lector de límerics. El lector no queda únicamente con una apreciación cómica y picante del asunto en cuestión, pues además percibe las palabras, los patrones fonéticos y rítmicos y el mensaje lascivo final como un medio material que le invita a adoptar frecuentemente una actitud prácticamente surrealista, acorde con el tema central del poema:

Said a certain Young maid of Tortuga,

"How I wish I could mate with a cougar.

The sheer joy of the matching

Would be worth all the scratching."

But her friends think she's clearly meshuggah (1978:22).

El gróseric anterior, cifra y compendio de la mayoría de gróserics de nuestro autor, es todo un patrón figurativo del estilo, el tono y el mensaje de una lírica con inspiración y vocación surrealistas donde el carácter transgresor de las doctrinas y fundamentos tradicionales del movimiento no reside, en cambio, en cuestiones políticas o sociales, sino en el sexo grosero, erigido en el núcleo de un sistema lingüístico, semántico y semiótico que constituye una hermenéutica del sexo lírico como eje central de un im-prudente surrealismo poético, que el propio Asimov justifica como un apartado más de su irreverente actitud literaria:

Of course, I am a little nervous over the fact that I myself happen to be the husband of a psychiatrist, and I have been called as mad as a hatter on occasion. However, as the title of the Limerick indicates, there is no personal reference here. I am not a satyr; just an ordinary hardworking male interested in what he does (1975:128).

Estos versos, que para ciertos lectores pueden suponer todo un arsenal y pesada munición de mal gusto, han de ser interpretados desde el humor, con un prescriptivo distanciamiento que pueda otorgar al destinatario lírico una visión de los mismos totalmente desprendida y alejada del mundo de la razón, para así percibirlos desde el reino de la intuición poética, cuando se aspira a transgredir y transformar nuestra convencionalista percepción del mundo:

The surrealists pay special attention to poetic intuition. They consider that poetic intuition involves some kind of nature that foresees all the different associations that the rationalistic world view prevents from perceiving. Thus, with the rules laid down in surrealism, the poet's major role will be to make the cognitive process go on one step further (MATTHEWS, 1976:92). 
Es precisamente mediante este nuevo «cognitive process» cuando el destinatario lírico puede captar la esencia del gróseric como noción irracional, abandonando así todo vestigio de insensibilidad. El hablante lírico ofrece un planteamiento surrealista del gróseric porque espera una idéntica respuesta o propuesta por parte de su destinatario lírico. De este modo, la comprensión del lector dependerá fundamentalmente de las variadas percepciones e impresiones intuitivas que le proporcionan estos versos, llevándole así a una intuición fenomenológica, que no introspectiva. Siguiendo este horizonte interpretativo, hablante y destinatario líricos confluyen y aprehenden una esencia del mundo que de otro modo sería insoportable e inaceptable:

$$
\begin{gathered}
\text { Annabelle turned beet-red in the face } \\
\text { At having been raped. Such disgrace! } \\
\text { Yet although it was terrible } \\
\text { It was not quite unbearable. }
\end{gathered}
$$

She had taken her pill just in case (1975:132).

Como vemos, la actitud surrealista del hablante y actante lírico de estos gróserics revela una doctrina de sustancia vital que remite a la actitud primitiva, y también transformada, en la medida en que es también el punto de partida de esta visión del sexo transgresora y liberadora, elemental y primaria, como ingrediente histórico de la naturaleza humana. No es por tanto el amor el combustible del fuego surrealista de estos versos, sino el crudo deseo animal, lascivo, impetuoso y brutal, que destapa al hombre prehistórico, dentro de su estado más primitivo de la mente, meditando ante el crudo fuego lascivo de un surrealista proceso lírico interior, desgarrador y al mismo tiempo liberador:

A gentleman shouldn't bring haste for it.

He must see that the lady is paced for it.

He must kindle the fire,

Raise it carefully higher,

Producing a connoisseur's taste for it (1981:46)

\section{4. ¿ LOS LÍMERICS O GRÓSERICS DE ASIMOV EN ESPAÑOL?}

El gróseric de nuestro poeta tiene su fuerza vital en la corpulenta norma métrica y expresiva que le confiere el ritmo anapéstico y vibrante de unos versos enfrentados a dos segmentos temporales claramente definidos: la realidad social del momento de su composición, y el flujo temporal del subconsciente de un hablante lírico marcado por una conciencia intelectiva que trasciende la naturaleza empírica del propio verso. Trasladar, por tanto, la cualidad recia y enérgica de estos patrones métricos y fonéticos del inglés al español entrañaría complejos y constantes escollos de los que, a título ilustrativo, se podrían especialmente destacar dos: el primero, la resistencia natural de los propios patrones sonoros y rítmicos del español, que no en pocas ocasiones obligaría al osado traductor a utilizarlo como una especie de improvisado «metalenguaje» con el que intentar describir y plasmar — con la mayor proximidad posible — el fuerte sistema sonoro de las impecables 
rimas y ritmos del original inglés, con toda la trascendencia expresiva que de ello también se deriva; y el segundo, seguramente el más arduo, el tratar de acercar el significado último del límeric resultante en español con la original intención lírica del poeta, y entiéndanse por 'original' ambas acepciones del término: la originalidad que confiere a cada límeric un carácter y un temple únicos y que lo hacen novedoso, y, por otra parte, la originalidad como chispazo causante y responsable del resultado último de la composición, confiriéndole así su singularidad.

La intención lírica de una posible y bienvenida traducción de estos límerics y gróserics de Asimov al español debería apostar por la fidelidad, en la medida de lo posible, a la relación entre las palabras, los sonidos producidos y los significados resultantes, siguiendo así las pautas que el poeta norteamericano Archibald MacLeish, en su canónico manifiesto poético Poetry and Experience, describiera como pilares esenciales del poema en cuanto a estructura de significación sonora:

The poem's meaning is evoked by the structure of words-as-sounds rather than by the structure of words-as-meanings. And the enhancement of meaning, which we feel in any true poem, is a product, therefore, of the structure of the sounds (MACLEISH, 1965:23).

Siguiendo esta premisa, para mantener el pulso poético y la intensidad sonora de estos límerics de la lengua inglesa en su versión española, el traductor se verá conminado a encontrar un punto de modulación entre «el realce del significado» y «la estructura de los sonidos» también en español, lo que hace que su función se aleje drásticamente del enfoque meramente descriptivo y traductológico, para albergar así el más puro sentido figurativo que concebiría su labor como una versión rimada del original en inglés. Recurrir únicamente a la «interpretación» conceptual del verso inglés, supondría cercenar en español los aspectos más líricos y alegóricos del límeric: la significación sonora y el simbolismo sonoro. Creemos, por tanto, que una futura versión rimada en español de los límerics y gróserics de Isaac Asimov hará también justicia a la particular semiótica de esta forma poética y a la original intuición lírica de un poeta que, como aspirante a buen políglota, no en pocas ocasiones también flirtea atrevida y jocosamente con ciertas mordaces rimas y significaciones de la lengua de Cervantes:

$$
\begin{aligned}
& \text { Érase un tipo de La Jolla } \\
& \text { que se tiraba a su mujer en la folla. } \\
& \text { Los que por allí pasaban } \\
& \text { bien que se trastabillaban, } \\
& \text { pero la folla era la polla. }{ }^{19}
\end{aligned}
$$

\footnotetext{
${ }^{19}$ Como conclusión del presente artículo, permítaseme la presente traducción del límeric original, atendiendo, lo más fielmente posible, los criterios ya expuestos en nuestro estudio: «There was a young man of La Jolla / Who kept screwing his wife in the folla. / Those who passed by would mumble / Or stub toes and stumble / But the folla was where he'd enjolla» (1981:24).
} 


\section{BIBLIOGRAFÍA}

Abrams, M. H., et al. (eds.) (2003): The Norton Anthology of English Literature, 2 vols., 7. a edición, Nueva York, Norton \& Company.

- (2012): The Fourth Dimension of a Poem and Other Essays, Londres.

ASIMOV, IsAaC (1975): AsIMov's LeCHERous LIMERICKS, LONDRES, CORGI BoOKS.

- (1971): The Sensuous Dirty Old Man, Nueva York, Walker \& Company.

- (1976): More Lecherous Limericks, Nueva York, Walker Publishing.

- (1977): Still More Lecherous Limericks, Nueva York, Walker Publishing.

- (1978): Asimov's Sherlockian Limericks, Nueva York, The Mysterious Press.

- (1978): Limericks: Too Gross or Two Dozen Dirty Dozen Stanzas, Nueva York, Norton \& Company.

- (1981): A Grossery of Limericks, Nueva York, Norton \& Company.

Doyle, Sir Arthur Conan (1998): The Complete Sherlock Holmes, Nueva York, Bantam.

- (2009): The Penguin Complete Sherlock Holmes, Londres, Penguin.

Garrity, Joan Terry (1970): The Sensuous Woman: The First How-To Book For the Female Who Yearns to Be All Woman, Nueva York, W. H. Allen.

Hoppa, Jocelyn (2009): Isaac Asimov, Science Fiction Trailblazer, Enslow Publishers, Berkeley Heights.

MacLeish, Archibald (1965): Poetry and Experience, Middlesex, Penguin.

Matthews, J. H. (1976): Toward the Poetics of Surrealism, Nueva York, Syracuse University Press.

Mendelson, Edward (1983): Early Auden, Cambridge, Harvard University Press.

- (1996): W. H. Auden, As I walked Out One Evening: Songs, Ballads, Lullabies, Limericks, and other Light Verse, Londres, Faber \& Faber.

Nash, Ogden (2008): Candy is Dandy: The Best of Ogden Nash, Londres, André Deutsch.

ShaKespeare, William (2000): Othello, Londres, Wordsworth Classics.

White, Michael (2005): Isaac Asimov: A Life of the Grand Master of Science Fiction, Nueva York, Carroll \& Graf Publishers. 